\title{
S. fi
}

\section{Studies in Second Language Learning and Teaching}

Department of English Studies, Faculty of Pedagogy and Fine Arts, Adam M ickiewicz University, Kalisz

\section{Book Review}

\section{Learning strategy instruction in the language classroom: Issues and implementation}

\author{
Editors: \\ Anna Uhl Chamot, Vee Harris \\ Publisher: \\ Multilingual Matters, 2019 \\ ISBN: \\ 978-1-78892-339-2 \\ Pages: \\ 296
}

The book Learning Strategy Instruction in the Language Classroom: Issues and Implementation, edited by Anna Uhl Chamot and Vee Harris, touches upon crucial issues pertaining to language learning strategies (LLS) and language learning strategy instruction $(\amalg \mathrm{SI})$, both from a theoretical and practical perspective. All the contributors to the volume are specialists with considerable expertise in the field of $L S$ and $\amalg S$, which makes the book an informative and inspirational read. The authors look at the concept of strategy instruction from different perspectives, meticulously not only investigating various LLSI models, taking account of "learner needs and settings and particular language skills," but also "considering curricula, materials, teachers roles, the ways in which scaffolding is enacted in the classrooms" (p. viii). Since the volume adeptly combines research into LLSI with its theoretical aspects and complexities, it will prove useful to practitioners and researchers alike. Delineating new directions in the field of LLSI, the edited collection is undoubtedly a valuable contribution to ongoing discussions about LLSI and its implementation in the classroom. 
The book opens with a foreword where the editors address the most pivotal questions which have garnered researchers' attention over the past few decades. Throughout the volume the authors examine miscellaneous LLSI-related areas with great precision and, importantly, respond "to the challenge for more detailed evidence of the exact nature of the intervention, the theoretical and methodological underpinnings, and careful examination of the key features such as the role of teacher feedback" ( $p$. vii). This is followed by a brief introduction in which Chamot and Harris discuss their motivation behind putting together the edited collection and briefly summarize the content of each of the chapters. As they admit, the volume is not meant to offer conclusive "solutions to the issues raised. Instead it hopes to offer possible research agenda for the future" ( $p . x x v)$. For this reason all the chapters close with a set of research questions posed by their respective authors.

The volume comprises 17 chapters forming four main parts - two theoretical and two more practical ones devoted to different ways of empowering teachers wanting to effectively introduce LLSI in their classrooms. Part One, "Issues: Models and contexts," comprises six chapters. In Chapter 1, "Language learning strategy instruction: Recent research and future directions," Luke Plonsky points out that while there have been numerous studies into LLSI, there has been considerably less interest in the effectiveness of different methods used to implement it. He expresses his disappointment with the fact that there has been a great number of research projects which resulted from "convenience, intuition and/or some level of idiosyncrasy" (p. 3) rather than from solid theoretical foundations. Plonsky also stresses that research into LLSI should focus more on investigating the relationship between effective strategy usage and proficiency, the context in which the language is taught, students' age and specific instructional settings. He also points to the need to explore other factors, such as the rationale for the design of LLSI, the type and number of strategies to be taught, students' needs, the activities used or the duration of the intervention. All of these variables and their impact on LLSI need to be investigated if we are "to fully understand the many implications of LLSI for both theory and practice" (p. 17).

The second chapter, "Approaches to learning strategy instruction," opens with a simple, yet powerful, pronouncement: "Strategic learning matters" ( $p$. 22). Peter Yongqi Gu defines the notion of strategic learning as "a dynamic and iterative process for solving a learning problem, boosting the learning speed or making the learning process more efficient, effective and probably more enjoyable" (p. 23). If strategic learning is to take place, the learner needs to possess declarative, procedural and conditional knowledge. While it seems natural for children to develop certain strategies in order to analyze, absorb and memorize new information, "we cannot assume that they will automatically discover and 
apply all the strategies they need on their own" (p. 22). That is why, if children are to learn more about strategies, they need to be exposed to strategy training. Gu also discusses different approaches to strategy instruction (SI) in first and second language acquisition as well as examining ways in which research into LLSI could inform classroom teaching.

Vee Harris's chapter “Diversity and integration in language learning strategy instruction" explores different factors that exert an impact on learners' strategy choice and deployment, such as age, gender, personality, but also learners' socioeconomic and sociocultural environment. In the first part, the author explores the ways in which these variables can be considered to inform LLSI. Paraphrasing Oxford and Schramm (2007), Harris argues that "it is time for $\amalg S$ research to explore how a sociocultural and psychological perspective can complement each other" (p. 39). The second part focuses on two different models of LLSI, that is, the Cognitive Academic Language Learning Approach (CALLA) and Strategic Content Learning $(\mathrm{SCL})$ as well as the manner in which they can be combined "to make the most of the rich diversity of students' social backgrounds" (p. 39).

In the fourth chapter, titled "Designing strategic classrooms: Self-assessment in enabling self-regulated learning," Do Coyle illustrates ways in which "learners can be effectively and appropriately empowered to engage in developing and adapting their environment and behaviors to become increasingly selfdirectional by planning, supporting, regulating, monitoring and assessing their own learning" (p. 54). This process could be facilitated by creating strategic learning spaces, "where learners and teachers work in partnership to enable successful learning to take place" (p. 55, Fullan \& Langworthy, 2014). The author explores four indispensable elements of such strategic learning spaces: goal-orientation, task-orientation, progression and making connections. Throughout the chapter Coyle also stresses the role of self-assessment, viewing it as "an integral and interdependent part of self-regulated learning within an ecological framework specifically seeking to foster learner autonomy" (p. 64). Effective self-assessment, however, requires close collaboration between the learner and the teacher, which undeniably constitutes a considerable challenge in the classroom.

In Chapter 5, "Language learner strategies and individual differences," Ernesto M acaro focuses on the link between LLS and individual differences (IDs). $\mathrm{He}$ is of the opinion that thanks to a meticulous analysis of "the possible interactions between LLS and ... IDs, researchers and (especially) teachers can secure a better long-term understanding of how L2 learning takes place over time" (p. 68). While there are numerous IDs that merit researchers' attention, the ones that, according to $M$ acaro, seem to be of paramount importance are selfefficacy and attribution. He argues that these two factors "can form an inherent part of a language assessment system" (p. 78), and thus future studies into LLSI 
should investigate the relationship between "these variables and their contribution to language assessment" (p. 78).

In the sixth chapter, entitled "Learning strategy instruction in content and language integrated learning programs," M arcella M enegale examines the relationship between Content and Language Integrated Learning (CLIL) and the deployment of different LLS: metacognitive, cognitive and social. The author argues that CLIL offers "a uniquely favorable environment for developing language learning strategies" (p. 82). This is because CLIL helps learners to get to know language strategies in "a more significant and authentic learning context compared to L2 classroom" (p. 82). M oreover, research has shown that learners participating in CLIL programs have a wider variety of LLS at their disposal than learners who have not been benefitted from this instructional mode.

The second part of the edited collection, "Issues: Less studied and less taught groups of strategies," brings together three chapters. It opens with the contribution by M irosław Pawlak "Grammar learning strategies instruction in the foreign language classroom: The case of students in degree programs in English." The author discusses different factors which need to be taken into account prior to implementing grammar learning strategies instruction (GLSI). He also outlines a comprehensive system of categorizing strategies for learning grammar which comprises four groups of LLS, namely, metacognitive, affective, social and cognitive. The main thrust of the chapter is the presentation of tentative principles of GLSI together with numerous suggestions concerning their implementation. Pawlak makes the point that if GLSI is to be effective, major changes need to be made with respect to how grammar is taught and tested. These changes seem pivotal since "as previous research has demonstrated (Pawlak 2009, 2012), many students have a tendency to approach learning grammar in a way that mirrors instructional practices and testing procedures" (p.119).

In Chapter 8, "Language learning strategy instruction for critical cultural awareness," Anna Uhl Chamot and Vee Harris examine one of the key elements of intercultural competence - critical cultural awareness (CCA), a concept which surely merits attention "in the current climate of mass migrations of peoples" (p. 124). Another reason why the authors zoom in on this particular area is that "although books, newspapers, poems and film can give advanced students considerable insight into cultures, some teachers of beginner students struggle to develop their lessons beyond simply discussing factual information (such as typical meals or the color of taxis)" (p.124). As the authors recognize, there is no research that would investigate the connection between CCA and LLSI. Therefore, the chapter explores a variety of LLS that could contribute to the development of CCA and offers suggestions as to how such strategies could be incorporated into classroom instruction. 
In the final chapter in Part Two, "Strategy instruction for learning and performing target language pragmatics," Andrew D. Cohen stresses the importance of pragmatic strategies, that is, strategies that "deal specifically with the comprehension and production of language when the underlying sociocultural intentions are not necessarily straightforward" (p. 142). Although there have been studies investigating pragmatic strategies in terms of $\mathrm{LLSI}$, the existing body of research is still scant compared to other strategy types. Moreover, to quote Cohen, "there are as yet few teacher development programs or programs of language instruction that give prime attention to pragmatics strategies" (p.142). The author offers a variety of tasks depicting how to explicitly teach "the strategies that more or less match the CALLA steps or raising awareness, modelling, practicing and evaluating pragmatics strategies" (p. 142). The chapter clearly signals a transition from a more theoretical part of the book to a more practical part which offers a wide range of activities and resources facilitating the implementation of LLSI.

Part Three, "Implementation: The learners," opens with the chapter "Designing effective strategy instruction: Approaches and materials for young language learners." Pamela Gunning, Joanna White and Christine Busque explore an area which so far has received relatively limited attention, namely LLSI among young language learners (YLLS). As they comment, this neglect stems from several factors, such as "a lack of resources, uncertainty about how to adapt abstract, complex concepts to YLLs' level, or concern that children lack the necessary metacognitive awareness" (p. 156). There are also other contentious issues pertaining to LLSI directed at YLLS which the authors enumerate, that is, the language of instruction, a suitable LLSI design or adept use of scaffolding, among others. Importantly, Gunning, White and Busque highlight effective ways of implementing LLSI among young language learners, placing emphasis on raising learners' awareness, identifying their needs, planning, reflection or modelling strategies.

The next chapter, "Guidelines and materials for integrating language learning strategy instruction into the language lesson" by Angeliki Psaltou-Joycey looks at the different ways of designing classroom materials that could help teachers integrate LLSI into their daily practice. The author also emphasizes the role that teachers play in the process of selecting and deploying LLS, especially among beginners and young learners. Therefore, practitioners need a great deal of support, for instance in the form of easily accessible and ready-to-use materials. The issues that Psaltou-Joycey believes merit attention while preparing activities to be employed in LLSI are "strategy and associated clusters, language skill/skills targeted, learners' education level or age, language proficiency level, description of the activity, teaching objective, teaching material (created/adjusted/existing)" (p. 173). She also highlights the importance of incorporating into LLSI two rather neglected strategy types, namely, compensation and affective LLS because they 
"help increase learner motivation and ... develop cultural knowledge and understanding which should start from an early age" (p. 176).

In Chapter 12, "Differentiation in language learning strategy instruction," Anna Uhl Chamot discusses the notion of differentiated instruction (DI) and the various ways in which teachers can apply it for LLSI. While we may observe differentiation in the classroom, "most frequently carried out in terms of content, process and/or product" (p. 185), it is difficult to find any clear guidelines that would show teachers how to successfully differentiate LLSI. Chamot also elaborates on the significance of developing learners' metacognitive knowledge which she describes as "the foundation of learning strategies and their most important component" (p. 185). She also describes a variety of tasks that could help teachers raise learners' metacognitive awareness.

The third part of the book closes with the chapter "Teaching language learning strategies using technologies," where Jill Robbins looks at the ways of integrating online learning materials and LLSI. Strategy use in online learning is a relatively new concept which has not generated a great deal of research thus far. However, with the upsurge of online learning opportunities it seems crucial to show learners how to explore strategies that could help them make more rapid progress. Robbins argues that "without explicit strategy instruction, learners may struggle if they try to exploit online resources without the necessary strategies" (p. 191). Another area which has sadly garnered even less attention from researchers is the employment of LLS when using social media to learn additional languages. Robbins makes the point that combining LLSI and social media use could exert a positive impact on language instruction "by providing models of strategic learning" (p. 208).

Part Four, titled "Implementation: The teachers," lays emphasis on the role of the teacher in developing learners' strategic competence. As Chamot and Harris point out, "there is little available guidance on integrating LLSI into pre- and in-service teacher education" (p. 211). However, prior to training learners in strategy selection and use, practitioners themselves need to display strategic awareness and reflect on their own strategy employment. The first chapter in this part, "Teacher education: Formative assessment, reflection and affective strategy instruction" by Christina Gkonou and Rebecca Oxford, stresses the significance of teachers' selfassessment and reflection in the process of implementing LLSI. The authors expound different types of reflection which might be conducive to successful LLSI application among language teachers. Gkonou and Oxford also address the notion of formative assessment in daily teaching practice as well as highlighting its role in learning more about their LLS use and the effectiveness of LLSI.

In the chapter "Empowering teachers to promote learner self-management" Joan Rubin and Claudio Acero Rios focus on language teachers who have tried implementing LLSI "but noted that they often fail to integrate it into their lessons in 
spite of exposure to the extensive literature on its value" (p. 227). The authors describe a teacher education program created to help pre- and in-service teachers develop self-directed learning (SDL) because they are strongly convinced that introducing learning self-management (LSM) strategies could significantly improve teachers' work and help them raise strategic awareness among their learners. The two metacognitive strategies that could help teachers gain greater insight into LSM are problem-identification and problem-solving strategies as well as setting SM ART goals when planning their lessons. By deploying these LLS in their daily teaching practice, teachers can set an example for students and "enable them to do the same" (p. 237).

In the next chapter, titled "Teacher education for language learning strategy instruction: Approaches and activities," Anna Uhl Chamot, Vee Harris, Carol Griffiths, Pamela Gunning, Martha Nyikos and Birsen Tutüniș highlight the different hindrances teachers are confronted with when implementing LLSI. The authors provide a set of useful LLSI principles that pre- and in-service teachers should take into consideration prior to introducing learners to language learning strategies. The chapter also offers a variety of LLSI teacher development tasks that could prove helpful to teachers wishing to introduce LLS in their classes. The contribution closes with examples of collaboration between researchers and teachers engaged in LLSI. By working closely together and sharing their invaluable experience, researchers and practitioners can gain greater insight into the challenges associated with familiarizing learners with LLS and also contribute to meaningful changes in the field of LLSI.

The final chapter of Part Four as well as the entire collection by Christine Goh, titled "What we still need to learn about language learning strategies instruction: Research directions and designs," explores LLSI-related areas which are in need of further empirical investigation. In particular, Goh argues that there is a need for more research projects that would examine strategic intervention and factors mediating it, such as learners' age, proficiency, motivation or self-efficacy, to name just a few. The author also stresses the need to base LLSI "on a set of sound theoretical principles" (p. 263). However, as she observes, providing a sound theoretical framework for LLS "remains one of the challenges in harmonizing the results of LLSI research and instructional approaches" (p. 263). Goh concludes her chapter by stressing the importance of "a coherent and effective LLSI program that teachers can use" (p. 273).

Finally, the afterword offers a summary of the most salient issues touched upon in the volume. Anna Uhl Chamot and Vee Harris also talk about their motivation behind the book - the editors wanted to elaborate on the wide array of multifaceted issues pertaining to LLSI, such as different models of LLSI, the principles underlying its implementation as well as teacher guidance. Since there is 
a shortage of volumes comprehensively addressing the field of LLSI, Learning Strategy Instruction in the Language Classroom: Issues and Implementation successfully fills the existing gap and will prove to be a valuable resource for anyone wishing to further explore or engage in strategic intervention, be it school educators or experienced researchers. What also makes this book unique are the questions for future research included at the end of each chapter. By adopting this approach, the editors successfully strive to "look into the future, suggesting further avenues to pursue" (p. 279). Moreover, being a language teacher myself, I found it refreshing and inspiring to see so many different and stimulating examples of activities that practitioners can easily utilize when attempting to implement LLSI. Unfortunately, teachers are incessantly pressed for time, trying to cover the required material within a limited amount of time; hence, including engaging, ready-to-use activities that could help them smoothly implement strategy instruction into their classes is surely is a commendable effort.

It goes without saying that the edited collection will be of enormous value to practitioners, materials writers, and researchers alike, providing them with comprehensive information on multifarious up-to-date issues in the domain of LLS and LLSI, the decisions involved in undertaking strategy instruction as well as the areas in this respect that are worthy of exploration. The book skillfully integrates theory and practice, which is why it will appeal not only to novice practitioners who are just about to embark on their journey with LLS but also to more experienced teachers who are already familiar with the concept of LLS and LLSI and wish to broaden their horizons in order to successfully implement strategy instruction in their everyday teaching practice. Most importantly, though, as the editors of this long-awaited volume thoughtfully conclude, "the chapters ... are a testament to how the LLS research community continues to be a vibrant, thriving and collaborative enterprise ready to respond to such challenges and well able to take on any new issues emerging in the future" (p. 282).

References

Reviewed by

Olga Trendak

University of Łódź, Poland olga.trendak@uni.lodz.pl

Oxford, R., \& Schramm, K. (2007). Bridging the gap between psychological and sociocultural perspectives on L2 learner strategies. In A. D. Cohen \& E. Macaro (Eds.), Language learner strategies: Thirty years of research and practice (pp. 47-68). Oxford: Blackwell. 
Pawlak, M. (2009). Grammar learning strategies and language attainment: Seeking a relationship. Research in Language, 7, 43-60.

Pawlak, M . (2012). Grammar learning strategies: State of the art. In L. Pedrazzini \& A. Nava (Eds.), Learning and teaching English: Insights from research (pp. 69-90). Monza: Polimetrica. 